\title{
A Post-COVID-19 Lifestyle Sport Research Agenda: Communication, Risk, and Organizational Challenges
}

\author{
William Roth Smith \\ Illinois State University
}

\begin{abstract}
The cancellations and postponements of large-scale organized sport competitions provided the first indicators of the impact that COVID-19 would have on society. During the pandemic, sport media reporting has focused on cancellations. Although not receiving as much media attention, "lifestyle sports," such as rock climbing, parkour, BMX, kayaking, or skateboarding, were also impacted by COVID-19 in ways that differ from organized team sports. In this commentary, the author draws upon select media reports and subcultural social media posts to highlight two primary impacts of COVID-19: (a) the civic organizational challenges of limiting lifestyle sport participation and (b) the influence on the social and risk-laden experience of these sports. The article concludes by detailing lifestyle sport stakeholder communication, digital sporting communities, the use of social media for organizing lifestyle sport communities, and sport risk communication as fruitful avenues for future research in a postpandemic lifestyle sports.
\end{abstract}

Keywords: community, social media, stakeholders

The National Basketball Association's suspension of the 2019-2020 season in mid-March, and the resulting domino-effect cancellations and postponements by sporting leagues and federations across the world, grabbed sport media headlines during the COVID-19 pandemic. Although not as prominently featured in mass media and often occurring outside of institutional or team settings, individualized action sports-often termed "lifestyle sports" (Wheaton, 2010, 2013), such as skateboarding, surfing, bicycle motor cross (BMX), parkour, or rock climbing, were not immune to COVID-19's effects. Stay-at-home orders, social distancing guidelines, and effects of the overall pandemic have impacted these sports differently than organized team sports. In this commentary, the author highlights the ways COVID-19 has affected lifestyle sports and then points to areas for future sport communication research.

The author (wrsmit1@ilstu.edu) is with the School of Communication, Illinois State University, Normal, IL, USA. 


\section{Differing Impacts on Lifestyle Sport}

The terms action, alternative, extreme, and adventure sport are used interchangeably to refer to individualized sports typically practiced outside of an organized team format. Although scholars have pointed out differences in the sports associated with the various monikers, the author's primary focus is on the individual aspect of these sports and the adoption of Wheaton's "lifestyle sports" moniker for this commentary. Lifestyle sports, such as kayaking, skateboarding, mountain biking, windsurfing, parkour have their own histories, identities, and idiosyncrasies but most run counter to traditional rule-bound team-based competitions. Many lifestyle sport athletes have an ambivalent attitude toward organized or structured competition and prefer an open environment "unhindered by regulations and controls by schools or sports organisations" (van Bottenburg \& Salome, 2010, p. 152). Skate parks, ocean swells, forests, mountains, BMX dirt jumps, urban streets, and ski slopes are the playing fields of lifestyle sport. Progression is measured through a sense of personal achievement, creativity, landing a specialized trick, or making a technical climbing ascent rather than points on a scoreboard.

Although many lifestyle sport athletes avoid organized contests, there are organized competitive outlets for lifestyle sports such as the Dew Tour, ESPN X Games, Vans BMX Pro Cup, and World Surf League Championship. All of these competitions were postponed by COVID-19. Whereas these media exhibitions are part of the lifestyle sportscape, the majority of participation occurs on an informal basis at public, private, and sometimes hidden user-built recreation areas. At first glance, it may seem that lifestyle sports outside of organized competition can continue as usual, particularly because they can be practiced on an individualized basis and do not require a team or large crowds of spectators-forms of social collectivity that would defy social distancing guidelines. However, lifestyle sport athletes and city governments have faced some unique challenges.

\section{Limited Participation}

Although the actions of lifestyle sports are individual, they are often practiced in close proximity to others. Government leaders are keenly aware of the social nature of lifestyle sports and have attempted to curb the virus' spread by limiting lifestyle sport participation at public skate parks, forests, parks, and beaches. Whereas a recreational sports league could effectively limit participation by canceling the remaining organized meetings and/or closing access to indoor facilities, civic leaders are finding challenges to curtail lifestyle sports at public beaches, outdoor skate parks, and bike trails. Cities across the United States, from Seaside, CA, to South Windsor, CT, took the measure of filling in concrete outdoor skate parks with sand or mulch to prevent athletes from congregating and violating social distancing guidelines. Sports such as skateboarding, BMX, and rollerblading are reliant upon city-sponsored skate parks, many of which closed during the pandemic. Alternatively, mountain biking, surfing, and outdoor rock climbing typically do not require a manufactured practice space. Although mountain biking and climbing occur in forests and deserts away from population-dense areas, land managers across the world have restricted access to municipal parks, nature preserves, and national forests. 
Government tactics to limit lifestyle sport participation have worked to varying degrees of success. For instance, city officials in San Clemente, CA, filled the skate park with sand, which encouraged dirt bikers to show up and ride the park (Asmelash, 2020). News stories about this incident showcased pushback from local residents and park users who proactively removed the sand or mulch to resume activities (see Figure 1). In another case, two men were cited for trespassing after sweeping off sand from a skate park in Connecticut (Dempsey, 2020). In addition, Sydney, NSW, Australia, erected fences to prevent surfing at the popular Bondi Beach location, but reports indicate many hopped the fence and disregarded the closure to ride the waves (Stonehouse, 2020). Surfers in Cannes, France, also defied government bans by surfing at the local beaches.

The virus created financial hardships for commercial lifestyle sport practice facilities. A review of international crowdfunding websites reveals that indoor rock climbing gyms and skate parks in Belgium, the Netherlands, England, and the United States are reaching out to the public for help in surviving the months without operating income. In other cases, lifestyle sport facilities were not temporarily closed but repurposed for the foreseeable future. For example, in Deeside, Wales, one of the largest indoor skate parks in Europe, was demolished not to curb lifestyle sport participation, but to make room for more hospital beds to treat recovering COVID-19 patients (Shaw, 2020; see Figure 2).

\section{The Experience of Lifestyle Sport}

Although governments attempted to limit participation in lifestyle sports, others encouraged lifestyle sports with restrictions. For example, exercises are typically
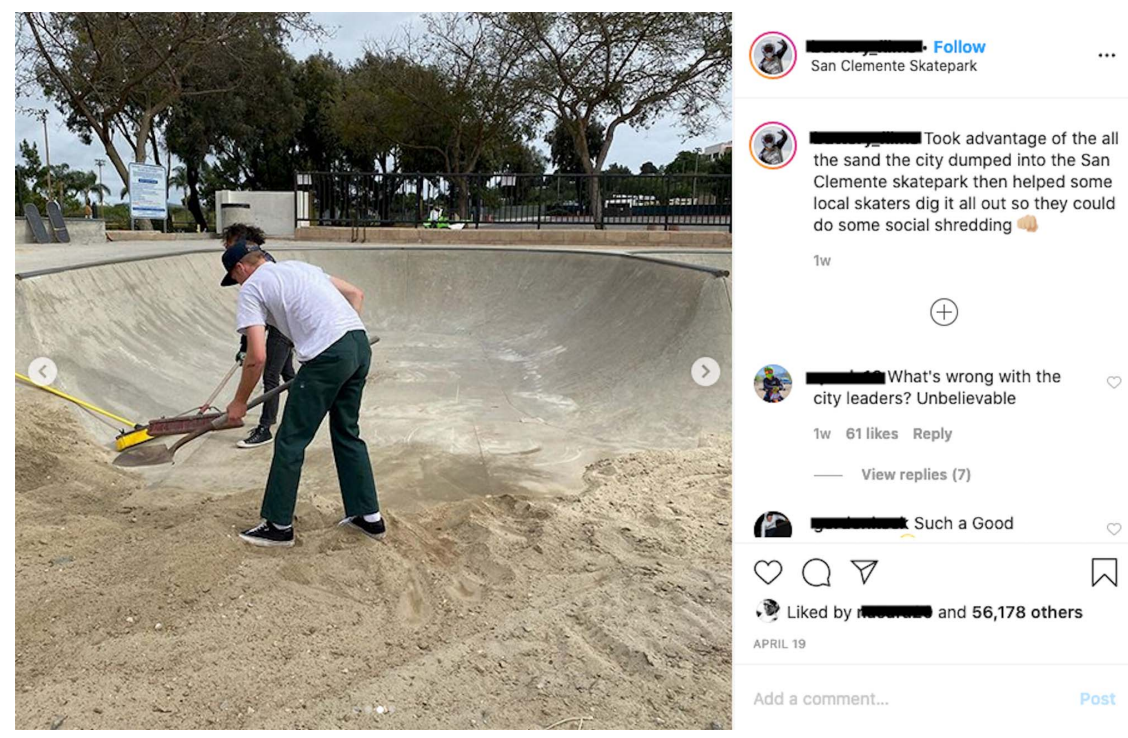

Figure 1 - Lifestyle sport athletes resisting city intervention. 


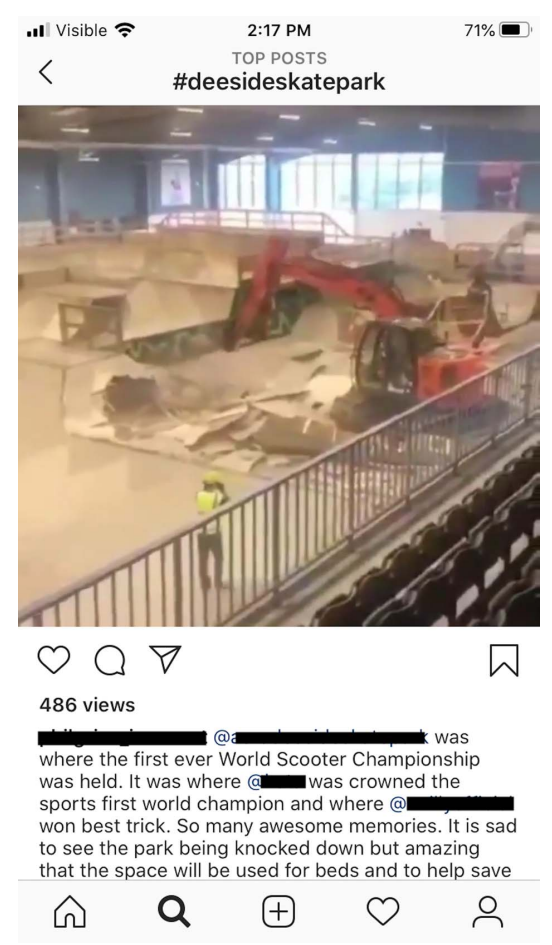

Figure 2 - Deeside Skate park, Deeside, Wales.

considered "essential," but people are urged to avoid doing so in groups and to stay in communities close to home. For instance, the World Health Organization launched the \#HealthAtHome campaign to encourage regular physical activity while maintaining social distance. Although these activities can continue even with stay-at-home orders in place, there are at least two common aspects of these sports affected by COVID-19: the social experience and the risky nature of the sport.

Prior research reveals that the appeal of lifestyle sports often lies in the sense of community, identity, belonging, and subculture generated by practicing the sport with others (Taylor \& Khan, 2011). In addition, athletes who participate in lifestyle sports are often drawn to the inherent risk of the sport (Clegg \& Butryn, 2012; Stranger, 1999). COVID-19 affected both of these factors. First, athletes have to maintain social distance in accordance with government and health organization guidelines, thus limiting the sports' social appeal. Second, athletes are told to practice the sport in a way that minimizes risk of injury so that they do not have to visit an already overcrowded health care system.

In particular, outsider discourses of lifestyle sports depict the activities as irresponsible or dangerous (Wheaton, 2013). A common argument against the construction of skate parks is that skaters have an increased risk of musculoskeletal injuries and fractures compared with other sports. This perception of skating as dangerous or risky may prompt local leaders to more severely limit lifestyle sport 
participation during the pandemic to slow the spread of COVID-19 and to prevent unnecessary hospital visits.

\section{A Post-COVID-19 Research Agenda for Lifestyle Sport}

There are several research directions that stem from attempts to limit lifestyle sport participation and its impact on the athletes' embodied experience. Specifically, lifestyle sport stakeholder communication, digital sporting communities, the use of social media for organizing lifestyle sport communities, and sport risk communication are avenues for future research.

\section{Lifestyle Sport Stakeholder Interactions}

The COVID-19 pandemic draws attention to the importance of advocacy and interactions between lifestyle sport groups and city governments, land owners, and the public. The difficulty that governments faced in restricting lifestyle sport participation-particularly on public beaches and skate parks-highlights the tensions in urban spatial politics. Older adults sometimes view skateboarding, BMX, and parkour in a negative light or consider the sports a public nuisance, particularly when practiced on public sidewalks, staircases, and other architecture. In locations that are already resistant to the construction of BMX or skate parks, the disregard of executive orders may further damage the relationships between lifestyle sport groups and land owners or government leaders. A brief review of news articles about the skate parks filled with sand revealed that lifestyle sport athletes took issue with the way the plan to limit participation was communicated. Others saw the sand as a double standard waged against skateboarders and BMXers when other mainstream sport recreation areas remained open (Child, 2020).

Sporting community and government interactions are rendered especially troublesome given that lifestyle sports are sometimes depicted as a "site of social resistance" (Beal, 1995), carry an "outlaw allure" (Carr, 2017), and often push back against authority figures. If lifestyle sport communities have an anti-authority ethos, then it is crucial to understand the types of communication that will be effective given these constraints. If participation cannot be restricted by canceling a league or locking the doors to a gym, then communication scholars should aim to understand who has influence within these sporting communities and explore the particular types of communication that will balance implementation of social distancing guidelines with the ethos of the sport. Scholars of sport governance may build upon established work by further investigating how the local actions of lifestyle sport athletes during the pandemic impact the future professionalization of lifestyle sport.

Community-city interactions are also important to study in a context that looks favorably on lifestyle sports. For instance, in the case of the public indoor skate park that was demolished in Wales, governments ultimately supported the park before the pandemic. The sports community may now need to further communicate with local civic leaders to ensure the park is rebuilt after the pandemic and not permanently repurposed. Similarly, it will be important to 
understand the communication of mountain biking advocacy groups as they navigate for land access and trail construction in private and public forests. Beyond public and private commercial sport centers, many lifestyle sport practice locations are crafted in an ad-hoc fashion by the participants themselves and are not reliant on income to operate. For instance, forgotten or derelict locations, such as bridge undersides, floodplains, or drainage ditches, are often "re-appropriated" (Wheaton, 2013) into clandestine skate parks or dirt BMX jumps. In other cases, these parks have local government approval but are constructed through volunteer actions (Vivoni, 2009). The economic fallout from COVID-19 likely foreshadows a decrease in government funding for lifestyle sport recreation areas. If lifestyle sport communities are willing to construct their own practice spaces without financial support from officials, then it will be crucial to understand communication-both among the athlete community and between civic administrators-that encourage contributions to these spaces and balances governmental or legal concerns.

\section{Digital Sporting Communities}

Communication scholars should also continue to investigate the community and social aspects of self-tracking and "quantified self" mobile fitness technologies. Prior research established that digital fitness tracking communities such as Strava (https://www.strava.com) are key sites for community building (e.g., Rivers, 2020). However, an interesting area for future research lies in parsing out the differences in how the practice of, and communication among, sporting participants may replicate, replace, or extend community aspects in virtual settings. For instance, individualized sports such as road or mountain cycling can take place inside the home on a stationary bicycle. Cycling training apps such as Zwift (Long Beach, CA) and RGT offered their services free to users during the pandemic, and Peloton (New York City, NY), which sells digitally connected stationary bicycles and treadmills that livestream workouts, saw an uptick in app downloads and subscriptions to the service. As these types of sports can be quantified (i.e., speed, distance traveled, calories burned), they are more amenable to uploading logged activities to online communities for commenting, liking, sharing, and even synchronous group rides through virtual landscapes. Conversely, sports like skateboarding, kayaking, or freestyle BMX may not be as adaptable to realtime digital community building because they cannot easily be practiced without access to a skate park, river, or BMX ramp. Furthermore, if progress in lifestyle sport is measured via personal accomplishment (e.g., learning a specialized maneuver), then it may be difficult to establish an online community like one would find on Strava. Although the field has turned considerable attention to the use of social media for established team sports, often tracking famous athletes' posts or interactions with fans, an alternative way of studying social media communication in a postpandemic society is to investigate how these tools afford community building and organizing of lifestyle sport communities.

\section{Lifestyle Sport Risk}

Future research should examine the types of communication that encourage athletes to practice their sports while minimizing risk. Although scholars could 
draw on sport communication research centered on concussion prevention, helmet use, and general injury prevention, there is one notable difference for lifestyle sports and the pandemic. The messages about risk during the pandemic seem to be less about risk avoidance simply for the sake of self-preservation (i.e., wear a helmet during sport to prevent damage to your head) but are framed in a way that highlights the larger implications of sustaining an injury during the pandemic (i.e., BMX-related hospital visits place an additional strain on overloaded health care systems). For example, popular mountain biking website Pinkbike.com adjusted the banner of their website to read "mountain biking irresponsibly during the COVID-19 pandemic puts you and others at risk. Avoid group rides and travelling to other communities." An area for future research lies in investigating how prominent lifestyle sport media outlets communicate about how to safely practice the sport while also minimizing the risks inherent to the activity plus the risk of spreading/contracting COVID-19.

Dominant media forms are one site to examine risk messages. However, Hutchins (2019) has already observed that the production, mediation, and consumption of sport are likely to shift from the dominant institutional technologies of broadcasting and print media to mobile forms. Thus, research could examine how lifestyle sport brands communicate about risk on social or mobile channels. For example, one BMX company sponsored a social media "quarantine challenge," where the follower who posts the best clip of a BMX trick filmed inside their home would win a free frame.

In addition to corporate social media, a hallmark of lifestyle sport is the creation and circulation of subcultural media. When there are few governing bodies, the self-regulation of these sports is often enacted by the athletes themselves through community and subcultural norms. For instance, the userbuilt Parisite DIY skate park in New Orleans, LA, largely communicates with lifestyle sport athletes through their Instagram handle. One such post during the pandemic (see Figure 3) encouraged park goers to maintain six feet of distance and wash their hands. Future research could consider how social media posts, hashtags, and other forms of social media discourse among the grassroots and organic corners of lifestyle sport participants communicate about mitigating the risk in an inherently risky sport and maintaining social distancing. Furthermore, if the embodied experience of lifestyle sport participation is characterized by risk, then scholars should investigate if the experience is the same when the risk is toned down or avoided.

In conclusion, moving forward, lifestyle sport scholars should be able to answer the following questions: How do lifestyle sport participants maintain a sense of community through digital mediums? How can lifestyle sport communities and stakeholder groups communicate for mutually beneficial outcomes? Does the digital mediation of lifestyle sporting activity influence the embodied experience of the activity? Is the experience of lifestyle sport qualitatively different when practiced in a risk-avoidant manner? How do lifestyle sport communities, brands, and media outlets communicate about COVID-19 risk and risk inherent to the sport across traditional and social media? As the effects of COVID-19 begin to taper, governments may ease restrictions on lifestyle sport participation. Nevertheless, the issues surfaced by COVID-19 may have lasting effects on sport participation and would prove valuable to understand even in a post-COVID-19 sportscape. 


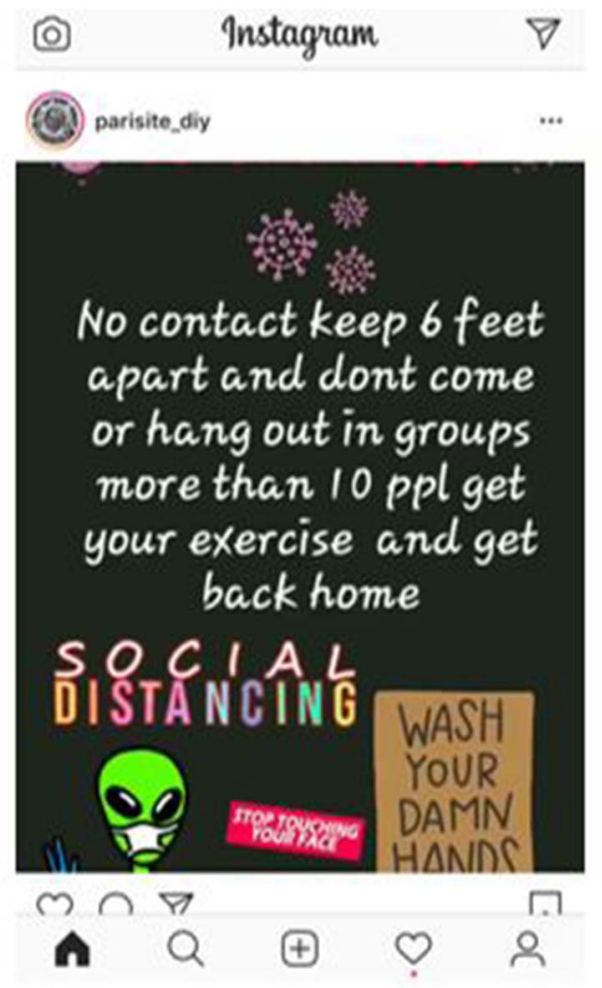

Figure 3 - Lifestyle sport community self-regulation.

\section{References}

Asmelash, L. (2020, April 22). A California city filled its skatepark with sand to deter skateboarders. Then the dirt bikers showed up. Retrieved from https://www.cnn.com/ 2020/04/22/us/skate-park-sand-venice-san-clemente-trnd/index.html

Beal, B. (1995). Disqualifying the official: An exploration of social resistance through the subculture of skateboarding. Sociology of Sport Journal, 12(3), 252-267. doi:10.1123/ssj.12.3.252

Carr, J.N. (2017). Skateboarding in dude space: The roles of space and sport in constructing gender among adult skateboarders. Sociology of Sport Journal, 34(1), 25-34. doi:10. 1123/ssj.2016-0044

Child, D. (2020, April 20). California city slams brake on skate park amid COVID-19 pandemic by filling it with sand. Retrieved from https://www.standard.co.uk/news/world/ california-skate-park-filled-with-sand-during-coronavirus-outbreak-a4419046.html

Clegg, J.L., \& Butryn, T.M. (2012). An existential phenomenological examination of parkour and freerunning. Qualitative Research in Sport, Exercise and Health, 4(3), 320-340. doi:10.1080/2159676X.2012.693527

Dempsey, C. (2020, April 3). Two men cited for trespassing at South Windsor skatepark shut down to stop spread of coronavirus. Retrieved from https://www.courant.com/ community/south-windsor/hc-br-south-windsor-closed-skate-park-trespass-coronavirus20200403-fwcs447gijcxtnf4r6nomocite-story.html 
Hutchins, B. (2019). Mobile media sport: The case for building a mobile media and communications research agenda. Communication \& Sport, 7(4), 466-487. doi:10. $1177 / 2167479518788833$

Rivers, D.J. (2020). Strava as a discursive field of practice: Technological affordances and mediated cycling motivations. Discourse, Context \& Media, 34. doi:10.1016/j.dcm. 2019.100345

Shaw, A. (2020, April 5). Deeside skatepark torn down by JCBs to make way for coronavirus field hospital. Retrieved from https://www.dailypost.co.uk/news/northwales-news/deeside-skate-park-torn-down-18046244

Stonehouse, G. (2020, April 24). Sydney beaches closed after crowds descend. Retrieved from https://www.canberratimes.com.au/story/6733872/sydney-beaches-closed-aftercrowds-descend/

Stranger, M. (1999). The aesthetics of risk: A study of surfing. International Review for the Sociology of Sport, 34(3), 265-276. doi:10.1177/101269099034003003

Taylor, M.F., \& Khan, U. (2011). Skate-park builds, teenaphobia and the adolescent need for hang-out spaces: The social utility and functionality of urban skate parks. Journal of Urban Design, 16(4), 489-510. doi:10.1080/13574809.2011.586142

Van Bottenburg, M., \& Salome, L. (2010). The indoorisation of outdoor sports: An exploration of the rise of lifestyle sports in artificial settings. Leisure Studies, 29(2), 143-160. doi:10.1080/02614360903261479

Vivoni, F. (2009). Spots of spatial desire: Skateparks, skateplazas, and urban politics. Journal of Sport and Social Issues, 33(2), 130-149. doi:10.1177/0193723509332580

Wheaton, B. (2010). Introducing the consumption and representation of lifestyle sports. Sport in Society, 13(7-8), 1057-1081. doi:10.1080/17430431003779965

Wheaton, B. (2013). The cultural politics of lifestyle sports. New York, NY: Routledge. 